\title{
Comparative Phytochemical analysis of stem and root extracts from Rauwolfia serpentina
}

\author{
Virendra Vaishnav ${ }^{1}$ and Debasish Sahoo $^{2}$ \\ 1,2 Nitza Bioventure, Hyderabad \\ Telangana, INDIA
}

\begin{abstract}
The aim of this study was to comparatively phytochemical analysis of stem and root extracts (acetone and chloroform) of Rauvolfia serpentine. It is also called sarpagandha, member of Apocynaceae family. It was admired from olden times used as an antidote of the snake and insects bites. Primary phytochemical analysis of root and stem extracts (acetone and chloroform) of Rauvolfia serpentina indicates the occurrence of alkaloids, tannins, flavonoids, phenols, carbohydrates, glycosides and terpenoids.
\end{abstract}

Keywords: Flavonoids, Sarpagandha, Apocynaceae, Glycosides, phytochemical.

\section{Introduction}

India has a wealthy heritage of Ayurvedic medicines and currently rush in require for plant-based drugs. Plants have showed a important role in managing human health and improving human life (Pandey et al. 2013). Rauwolfia serpentina (Linn.) is a medicinal shrub or herb, from Apocynaceae family. Rauwolfia serpentine one of the well-known antipsychotic and tranquilizer herb of India for schizophrenia and paranoia treatment as well as also control hypertension and high blood pressure. Rauwolfia serpentine generally called 'snake root' or Sarapgandha as well as called as a "Wonder drug of India". Sarapgandha has been more than a few years ago that the drugs of plan origin are using to cure of the diseases in man \& animals.

In Ayurvedic description, the powdered root of Rauwolfia serpentina has been used for the feverish illnesses as well as treatment of snake bites and mental illness (Chopra, R.N et al., 2002). Rauwolfia serpentina also shown pharmaceutical importance such as antidysentry, antimicrobial, anticancerous , tranquillizing activity, anti-inflammatory, antioxidant, antiproliferative, , antidiuretic, antiarrhythmic, anticholinergic, antidiarrhoeal, antihypotensive, anticontractile, antifibrillar and sympathomimetic (Arts, I.C. et al., 2005; Scalbert,
A. et al., 2005; Harisaranraj, R et al., 2009; Ezeigbo, I.I. et al., 2012; Yu, J. et al., 2013; Rathi, P. et al., 2013).

The Rauwolfia serpentine is abundant source of alkaloids presence of $1.7 \%$ to $3.0 \%$ in roots. Root and bark are rich alkaloidal source. It is contents $90 \%$ of the total alkaloids. Sarpagandha also an significant medicinal plant in the pharmaceutical industries presence of its colossal beneficial properties for curing diseases due to the presence of flavonoids, alkaloids, phenols, glycosides, tannins , phlobatannins, resins, sterols, saponins and terpenes (Harisaranraj, R et al., 2009).

The root, stem and leaves are medicinally significance and paying attention of researchers because of secondary metabolites contained mostly in the roots and rhizomes (Mittal B et al., 2012; Poonam et al., 2013). Scientists have been working on the phytochemical analysis of the plant due to its medicinal importance. It has been used as anthelmintic and anti-hypertensive drugs.

The present study was comparatively phytochemical analysis of Rauwolfia serpentina stem and root extracts and qualitative analysis of their different bioactive compounds which were presence in root and stem extracts.

\section{Materials and Methodology}

\subsection{Plant Materials}

The Rauwolfia serpentine stem and root were collected from Kanker district of Chhattisgarh, India. The collected stem and root were washed and surface sterilized and dried in shade. After drying samples were grinded with the help of mortar pestle.

\subsection{Chemicals}

All the chemicals used in this examination were of analytical reagent grade and procured from sigma, Merck etc. 


\subsection{Preparation of Extracts}

10 grams of grinded stem and root of Rauwolfia serpentina were dissolved in $100 \mathrm{ml}$ of solvents (Acetone and Chloroform) and kept for 24 hours in an orbital shaker at $28^{\circ} \mathrm{C}$. The extracts were filtered and filtrate extracts were evaporated and obtained residues were resuspended to their respective solvents.

\subsection{Phytochemical Screening}

The root and stem extracts of Rauwolfia serpentina were tested for primary screening of phytochemicals includes alkaloids, carbohydrates, flavonoids, Tannins, steroids, phenols. (Tiwari P. et al.,2011; Rathore S. K. et al.,2012)

\section{Test for Alkaloids (Wagner's Test)}

$1 \mathrm{ml}$ of extracts was added few drops of Wagner's reagent. Formation of reddish brown precipitate indicated the presence of alkaloids.

\section{Test for Carbohydrates (Molisch's Test)}

$1 \mathrm{ml}$ extracts was added 3-5 drops of molisch's reagent along with added $1 \mathrm{ml}$ con. $\mathrm{H}_{2} \mathrm{SO}_{4}$. Allowed the mixture to stand for 3-4 minutes. Observed red or dull violet colour at the interface of the two layers showed the presence of the carbohydrates.

\section{Test for Flavonoids (Alkaline Reagent Test)}

$1 \mathrm{ml}$ extract was treated with 3-5 drops of $20 \%$ sodium hydroxide solution. Observed formation of intense yellow colour, which became colourless on addition of dilute acid, indicated the presence of flavonoids.

\section{Test for Saponins (Foam Test)}

$1 \mathrm{ml}$ extract was shaken with $2 \mathrm{ml}$ of water. If foam produced persists for $10-15$ minutes then that indicates the presence of saponins.

\section{Test for phenols (Ferric Chloride Test)}

$1 \mathrm{ml}$ of extract was taken and 5-6drops of aqueous $\mathrm{FeCl} 3$ was added. The formation of deep blue colour indicated the presence of phenols.

\section{Test for Tannins (braymer's Test)}

$1 \mathrm{ml}$ of extract treated with $1 \mathrm{ml}$ of $10 \%$ alcoholic ferric chloride. Formation of blue and greenish colour indicated the presence of tannins.

\section{Test for Cardiac Glycosides (Legal's Test)}

$1 \mathrm{ml}$ extracts was treated with sodium nitropruside in pyridine and sodium hydroxide. Observed the formation of pink to blood red colour indicates the presence of cardiac glycosides.

\section{Results and Discussion}

$R$. serpentina has been a well-known field for study because of its various bioactive compounds those were used in herbal and dietary supplements as a capable source of helpful drugs for the healing of many diseases (Kumari, R et al., 2013). The results of phytochemical screening of stem and root extracts (Acetone and Chloroform) of Rauwolfia serpentina shown in table 1. Acetone root extract was shown positive results includes alkaloids, flavonoids, phenols, carbohydrates, tannins, protein, terpenoids and glycosides while saponins and anthroquinon were absent whereas Acetone stem extract showed positive results includes alkaloids, flavonoids, phenols, carbohydrates, tannins, protein, terpenoids, glycosides saponins and anthroquinon.

On other hand chloroform root extract of Rauwolfia serpentine was shown presence of phytochemical such as alkaloids, flavonoids, carbohydrates, glycosides and terpenoids while phenols, tannins, saponins, protein and anthroquinon were absent in the extract and chloroform stem extract observed presence of phytochemicals like alkaloids, flavonoids, carbohydrates, terpenoids and anthroquinon as well as phenols, tannins, saponins, glycosides, and protein were shown absent in chloroform stem extract.

Table 1. Primary Phytochemical Screening of Rauwolfia serpentina Stem and Root Extracts.

\begin{tabular}{|l|c|c|c|c|}
\hline $\begin{array}{c}\text { Phytochemic } \\
\text { als }\end{array}$ & $\begin{array}{c}\text { Aceton } \\
\text { e Root } \\
\text { Extrac } \\
\mathbf{t}\end{array}$ & $\begin{array}{c}\text { Acetone } \\
\text { Stem } \\
\text { Extract }\end{array}$ & $\begin{array}{c}\mathbf{C H C l}_{3} \\
\mathbf{R o o t} \\
\text { Extract }\end{array}$ & $\begin{array}{c}\mathbf{C H C l}_{3} \\
\mathbf{S t e m} \\
\mathbf{E x t r a c t}\end{array}$ \\
\hline Alkaloids & + & + & + & + \\
\hline Flavonoids & + & + & + & + \\
\hline Phenols & + & + & - & - \\
\hline Carbohydrate & + & + & + & + \\
\hline Tannins & + & + & - & - \\
\hline Saponins & - & + & - & - \\
\hline Glycosides & + & + & + & - \\
\hline Terpenoids & + & + & + & + \\
\hline Proteins & + & + & - & - \\
\hline Anthroquinon & - & + & - & + \\
\hline
\end{tabular}

\section{Conclusions}

Phytochemical investigation of root and stem extracts (Acetone and Chloroform) of Rauwolfia serpentina indicates the presence of alkaloids, flavonoids, terpenoids, glycosides and carbohydrates. In acetone root extract saponins was absent while acetone stem extract indicates positive result for saponins. On other hand chloroform root extract was shown positive result for glycosides but chloroform stem extract was recorded absent. Therefore, the occurrence of high level of alkaloids in the stem and root extracts of Rauwolfia 
serpentina may dependable for the biological activity of the nutritional supplementation. Evid Based samples. Thus, this study evaluated that the Rauwolfia Complement Alternat Med. 2013; 2013:376327. serpentina plant could be used as a natural medicinal agent.8. Poonam, Agrawal S and Mishra S, Journal of

\section{Reference}

1. Arts, I.C.; Hollman, P.C. Polyphenols and disease risk in epidemiologic studies. Am. J. Clin. Nutr., 2005, 81(1)(Suppl.), 317S-325S. [PMID: 15640497]

2. Chopra, R.N.; Nayar, S.L.; Chopra, I.C. Glossary of Indian Medicinal Plants. NISCIR; CSIR: Delhi, 2002.

3. Ezeigbo, I.I.; Ezeja, M.I.; Madubuike, K.G.; Ifenkwe, D.C.; Ukweni, I.A.; Udeh, N.E.; Akomas, S.C. Antidiarrhoeal activity of leaf methanolic extract of Rauwolfia serpentina. Asian Pac. J. Trop. Biomed., 2012, 2(6), 430-432.

4. Harisaranraj, R.; Suresh, K.; Babu, S.S. Phytochemical based strategies for pathogen control and antioxidant capacities of Rauvolfia serpentina Extracts. Recent Res. Sci. Technol., 2009, 1, 67-73.

5. Kumari, R.; Rathi, B.; Rani, A. Bhatnagar, S. Rauvolfia serpentina L. Benth. ex Kurz. Phytochem. Pharmacological and Therapeutic Aspects. Int. J. Pharm. Sci. Rev. Res., 2013, 23(2), 348-355.

6. Mittal B, Meenakshi, Sharma A and Gothecha V $\mathrm{K}$, International Journal of Ayurvedic \& Herbal Medicine, 2012, 2(3), 427-434.

7. Pandey MM, Rastogi S, Rawat AK. Indian traditional ayurvedic system of medicine and Pharmacy and Biological Science, 2013, 6(2), 7378.

9. Rathi, P.; Kumari, R.; Chatrasal, S. Therapeutic characteristics of Rauvolfia serpentina. Int. J. Pharm. Pharm. Sci., 2013, 2(2), 1038-1042.

10. Scalbert, A.; Manach, C.; Morand, C.; Rémésy, C.; Jiménez, L. Dietary polyphenols and the prevention of diseases. Crit. Rev. Food Sci. Nutr.,2005, 45(4), 287-306.

11. Tiwari P, Kumar B, Kaur M, Kaur G and Kaur H, Internationale Pharmaceutica Sciencia, 2011, 1(1), 98- 106.

12. Rathore S K, Bhatt S, Dr. Dhyani S and Jain A, International Journal of Current Pharmaceutical Research, 2012, 4(3), 160-162.

13. Yu, J.; Ma, Y.; Drisko, J.; Chen, Q. Antitumor activities of Rauvolfia vomitoria extract and potentiation of carboplatin effects against ovarian cancer. Curr. Ther. Res. Clin. Exp., 2013, 75, 814. 